\title{
Mobile phone usage does not affect sudden sensorineural hearing loss
}

\author{
D SAGIV ${ }^{1,2}$, L MIGIROV $^{1,2}$, O MADGAR $^{1}$, G NAKACHE $^{1}$, M WOLF $^{1,2}$, Y SHAPIRA $^{1,2}$ \\ ${ }^{1}$ Department of Otolaryngology - Head and Neck Surgery, Sheba Medical Center, Tel Hashomer, and \\ ${ }^{2}$ Sackler Faculty of Medicine, Tel Aviv University, Israel
}

\begin{abstract}
Objective: Recent studies found that mobile phone users had a significantly greater risk of having elevated thresholds in speech frequencies. This study investigated the correlation between the laterality of sudden sensorineural hearing loss, handedness and the preferred ear for mobile phone use.

Methods: The study included all patients who presented with sudden sensorineural hearing loss to the Department of Otolaryngology - Head and Neck Surgery in our tertiary referral medical centre between 2014 and 2016. Patients were asked to indicate their dominant hand and preferred ear for mobile phone use.

Results: The study comprised 160 patients. No correlation was found between the dominant hand or preferred ear for mobile phone use and the side of sudden sensorineural hearing loss. There was no correlation between the side of the sudden sensorineural hearing loss (preferable or non-preferable for mobile phone use) and audiometric characteristics.

Conclusion: No correlation was found between the laterality of ears used for mobile phone and sudden sensorineural hearing loss.
\end{abstract}

Key words: Cell Phones; Hearing Loss, Sensorineural; Hearing Loss, Sudden; Functional Laterality

\section{Introduction}

Mobile phone use has increased rapidly, with almost 6.9 billion subscribed mobile phone users in 2014 . $^{1}$ Consequently, there has been increasing concern regarding the potential hazardous effect of exposure to the electromagnetic radiation emitted from these devices. The biological effect of the electromagnetic radiation emitted by mobile phones includes a small rise in tissue temperature of adjacent organs, an alternation in the permeability of the blood brain barrier and increased levels of oxidative stress. ${ }^{2-5}$ A significant positive correlation between exposure to radiation and the incidence of vestibular schwannoma was demonstrated in few studies while contradicted in others. ${ }^{2,5,6}$ Though conflicting evidence exists, it has been suggested that these radiofrequency fields should be classified as a 'probable' human carcinogen. ${ }^{7}$

No interaction between mobile phone usage and auditory function was demonstrated when testing several audiological parameters. ${ }^{8-11}$ However, a few recent studies did find that mobile phone users had a significantly greater risk of having elevated thresholds in the speech frequencies ${ }^{9}$ or high frequencies (above 8 $\mathrm{kHz}){ }^{10,11}$ and absent distortion product otoacoustic emissions. $^{9,10}$
Sudden sensorineural hearing loss (SNHL) usually presents in an acute manner, mostly unilaterally, and can be accompanied by tinnitus, ear fullness or vertigo. The estimated annual incidence is 5-20 per 100,000 , and this symptom is probably underdiagnosed. $^{12,13}$ Sudden SNHL is usually idiopathic, and less than one-third of all cases are attributed to haemorheological disturbances, viral infections and autoimmunological mechanisms. ${ }^{14}$

Taking into account the literature correlating biochemical changes and neural damage, ${ }^{2-5}$ SNHL and long-term mobile phone usage, ${ }^{9-11}$ and patients' reports upon admission, we hypothesised that sudden SNHL might be somehow influenced or even triggered by mobile phone usage. We aimed to investigate, for the first time, the correlation between the laterality of sudden SNHL, handedness and the ear preferred for mobile phone use.

\section{Materials and methods}

The study included all patients who presented with first-time sudden SNHL in the out-patient clinic or the emergency room of the Department of Otolaryngology - Head and Neck Surgery in the tertiary referral Sheba Medical Center between March 
2014 and September 2016. Sudden SNHL was defined as a unilateral SNHL that developed within 3 days, verified by $30 \mathrm{~dB}$ or higher elevation of the bone conduction threshold in three consecutive frequencies (compared to a previous audiology test or to the better hearing ear). Demographic data, personal medical history, treatment and audiology test results were retrospectively retrieved from the patients' charts.

Patients were asked upon presentation in our hospital whether they use their mobile phone on a daily basis (the exact duration of usage per day was not quantified), what their dominant ear was (for mobile phone usage) and what their dominant hand was (for writing). All patients were referred to magnetic resonance imaging.

Exclusion criteria included: patients aged less than 18 years, previous history of sudden SNHL, previous otological surgery, final diagnosis of Ménière's disease, vestibular schwannoma or autoimmune inner-ear disease, and patients who reported that they hardly or never use a mobile phone.

The correlation between handedness, the dominant ear for mobile phone use and sudden SNHL laterality was investigated. Treatment protocols were out of the focus of the current study. The present study was approved by the Sheba Medical Center Institutional Review Board.

\section{Statistical analysis}

The mean and standard deviation of each measurement were determined. The student $t$-test and the chi-square test were applied to compare demographic, clinical and audiometric test results.

\section{Results}

The study included 178 patients with first-time sudden SNHL. Fourteen patients (7.9 per cent) were excluded because of Ménière's disease and autoimmune innerear disease, and four patients (2.2 per cent) were excluded because of vestibular schwannoma. Of the 160 patients with a final diagnosis of first-time sudden SNHL, 82 patients (51.3 per cent) were male and the mean age was 53.2 years (range, $19-84$ years).

At presentation, the severity of the sudden SNHL was, in order of prevalence: moderate $(n=44 ; 27.5$ per cent), severe $(n=43 ; 26.9$ per cent), profound $(n=34 ; 21.25$ per cent), moderate-to-severe $(n=29$; 18.1 per cent) and mild $(n=10 ; 6.25$ per cent). The mean speech reception threshold and speech discrimination score were $60.8 \pm 27.7 \mathrm{~dB}$ and $45 \pm 40.3$ per cent, respectively (Table I). The audiogram curve was: flat (all frequencies involved) in 52 cases ( 32.5 per cent), down-sloping (involving high tones) in 44 cases (27.5 per cent), up-sloping (involving low tones) in 29 cases (18.1 per cent) and U-shaped in 19 cases (11.9 per cent); 16 cases (10 per cent) had other types of audiogram.

No correlation was found between the dominant hand or dominant ear and the side in which the sudden SNHL presented (Table II). In addition, there was no correlation between the side of the sudden SNHL (whether on the dominant or non-dominant side) and audiometric test parameters before or after treatment (level of hearing loss, speech reception threshold, speech discrimination score and the morphological feature of the pure tone threshold), nor with the clinical course of the disease (Table I).

\begin{tabular}{|c|c|c|c|}
\hline COMPARISON BETWEEN & $\begin{array}{l}\text { TABLE } \\
\text { ITH SUDDEN SNHL IN EA } \\
\text { MOBILE PHON }\end{array}$ & ERAL VERSUS CONTRALA & IDE OF \\
\hline Parameter & $\begin{array}{l}\text { Sudden SNHL ipsilateral to } \\
\text { mobile phone use }\end{array}$ & $\begin{array}{l}\text { Sudden SNHL contralateral to } \\
\text { mobile phone use }\end{array}$ & $P$-value \\
\hline Number of patients $(n(\%))$ & $82(51.2)$ & $78(48.8)$ & - \\
\hline Gender $(n(\%))$ & & & 0.589 \\
\hline - Males & $44(53.7)$ & $38(48.7)$ & - \\
\hline - Females & $38(46.3)$ & $40(51.3)$ & - \\
\hline Mean age (mean $\pm \mathrm{SD}$; years) & $53.3 \pm 16.9$ & $53.2 \pm 15.0$ & 0.968 \\
\hline Vestibular events* $(n(\%))$ & $20(24.4)$ & $12(15.4)$ & 0.168 \\
\hline Audiogram $(n(\%))$ & & & 0.537 \\
\hline - All frequencies involved & $28(34.1)$ & $24(30.8)$ & - \\
\hline - High tone loss & $22(26.8)$ & $22(28.2)$ & - \\
\hline - Low tone loss & $15(18.3)$ & 14 (17.9) & - \\
\hline - 'Cookie bite' audiogram & $11(13.4)$ & $8(10.3)$ & - \\
\hline - Other (type of audiogram) & $6(7.4)$ & $10(12.8)$ & - \\
\hline Mean SRT $($ mean $\pm \mathrm{SD} ; \mathrm{dB})$ & & & \\
\hline - At diagnosis & $59.6 \pm 25.8$ & $62.2 \pm 29.6$ & 0.551 \\
\hline - After treatment & $36.8 \pm 27.7$ & $41.3 \pm 28.6$ & 0.348 \\
\hline - Improvement & $22.7 \pm 24.9$ & $20.9 \pm 21.0$ & 0.191 \\
\hline Mean SDS (mean \pm SD; \%) & & & \\
\hline - At diagnosis & $43.3 \pm 40.8$ & $46.4 \pm 40.0$ & 0.628 \\
\hline - After treatment & $66.1 \pm 37.5$ & $65.3 \pm 34.6$ & 0.912 \\
\hline - Improvement & $22.7 \pm 34.8$ & $18.9 \pm 35.2$ & 0.284 \\
\hline
\end{tabular}

${ }^{*}$ Patients who described any complaints of true vertigo in the course of the current disease. SNHL $=$ sensorineural hearing loss; $\mathrm{SD}=$ standard deviation; SRT $=$ speech reception threshold; SDS $=$ speech discrimination score 


\begin{tabular}{lllll}
\multicolumn{5}{c}{ TABLE II } \\
\multicolumn{5}{c}{ HAND, EAR AND SUDDEN SNHL LATERALITY } \\
\hline Parameter & $\begin{array}{l}\text { All } \\
\text { patients }\end{array}$ & $\begin{array}{l}\text { Right } \\
\text { sudden } \\
\text { SNHL }\end{array}$ & $\begin{array}{l}\text { Left } \\
\text { sudden } \\
\text { SNHL }\end{array}$ & $P$-value \\
\hline $\begin{array}{l}\text { Dominant hand* } \\
\text { - Right }\end{array}$ & $144(90)$ & $79(54.9)$ & $65(45.1)$ & 0.2 \\
$\begin{array}{l}\text { - Left } \\
\text { Dominant ear }\end{array}$ & $16(10)$ & $7(43.8)$ & $9(56.2)$ & \\
- Right & $124(77.5)$ & $66(53.2)$ & $58(46.7)$ & 0.403 \\
- Left & $36(22.5)$ & $20(55.6)$ & $16(44.4)$ & \\
\hline
\end{tabular}

Data represent numbers (and percentages) of patients, unless indicated otherwise. ${ }^{*}$ Defined by the hand used for writing. ${ }^{\dagger}$ Defined by the ear preferred for mobile phone use. SNHL = sensorineural hearing loss

\section{Discussion}

A large corpus of evidence supports the hazardous potential of electromagnetic radiation emitted by mobile phones on brain tissue and neurons, including apoptosis induced by the increased level of oxidative stress biomarkers. ${ }^{2-4}$ However, to the best of our knowledge, our study showed for the first time that mobile phone usage does not affect sudden SNHL.

- Mobile phone use has increased rapidly, with almost 6.9 billion subscribed mobile phone users in 2014

- Some studies, but not others, have shown a positive correlation between vestibular schwannoma and radiation exposure

- In some recent studies, mobile phone users had greater risk of elevated thresholds in speech frequencies and absent distortion product otoacoustic emissions

- This is the first study to examine the correlation between mobile phone usage and sudden sensorineural hearing loss (SNHL)

- The cohort comprised 160 patients who experienced sudden SNHL for the first time

- Sudden SNHL laterality was independent of the laterality of the ear preferred for mobile phone use

Lateralisation of the auditory system is described as an asymmetry found in different levels of the auditory pathway that is already evident in newborns. In normal listeners, right ear preponderance is usually described based on auditory brainstem response measurements, otoacoustic emissions, responses to speech stimuli and different speech perception test results, whereas the left ear is supposed to be superior in non-verbal sound presentation (including brief melodies) and intonation discrimination. ${ }^{15,16}$ For the purpose of the current study, we defined the dominant ear as the ear that is usually preferred for mobile phone use.

Though exposure to radiation from mobile phones is highest in the temporal lobe, ipsilateral to the side of phone usage, ${ }^{5}$ we found that the side of sudden SNHL was almost equally divided between right ( 53.75 per cent; $n=86)$ and left (46.25 per cent; $n=74)$. No correlation was found between the laterality of the ear preferred for mobile phone use or between the dominant hand (known to affect the preferred ear ${ }^{16}$ ) and the side of sudden SNHL (Table II).

To conclude, this large cohort of 160 consecutive cases of first-time sudden SNHL demonstrates for the first time that there is no significant correlation between mobile phone usage and sudden SNHL. Future investigations should model the characteristics of common mobile phones and type of radiation involved, the amount of exposure and its latency in the patient population.

\section{References}

1 World Health Organization. Electromagnetic fields and public health: mobile phones (Fact sheet number 193). In: http:// www.who.int/mediacentre/factsheets/fs193/en/ [17 October 2016]

2 Benson VS, Pirie K, Schüz J, Reeves GK, Beral V, Greem J et al.; Million Women Study Collaborators. Mobile phone use and risk of brain neoplasms and other cancers: prospective study. Int J Epidemiol 2013;42:792-802

3 Eberhardt JL, Persson BR, Brun AE, Salford LG, Malmgren LO. Blood-brain barrier permeability and nerve cell damage in rat brain 14 and 28 days after exposure to microwaves from GSM mobile phones. Electromagn Biol Med 2008;27:215-29

4 Motawi TK, Darwish HA, Moustafa YM, Labib MM. Biochemical modifications and neuronal damage in brain of young and adult rats after long-term exposure to mobile phone radiations. Cell Biochem Biophys 2014;70:845-55

5 Hardell L, Carlberg M, Söderqvist F, Mild KH. Case-control study of the association between malignant brain tumours diagnosed between 2007 and 2009 and mobile and cordless phone use. Int J Oncol 2013;43:1833-45

6 Alexiou GA, Sioka C. Mobile phone use and risk for intracranial tumors. J Negat Results Biomed 2015;14:23

7 Morgan LL, Miller AB, Sasco A, Davis DL. Mobile phone radiation causes brain tumors and should be classified as a probable human carcinogen (2A) (review). Int J Oncol 2015;46: 1865-71

8 Sudan M, Kheifets L, Arah OA, Olsen J. Cell phone exposure and hearing loss in children in the Danish National Birth Cohort. Paediatr Perinat Epidemiol 2013;27:247-57

9 Panda NK, Modi R, Munjal S, Virk RS. Auditory changes in mobile users: is evidence forthcoming? Otolaryngol Head Neck Surg 2011;144:581-5

10 Panda NK, Jain R, Bakshi J, Munjal S. Audiologic disturbances in long-term mobile phone users. J Otolaryngol Head Neck Surg 2010;39:5-11

11 Velayutham P, Govindasamy GK, Raman R, Prepageran N, Ng $\mathrm{KH}$. High-frequency hearing loss among mobile phone users. Indian J Otolaryngol Head Neck Surg 2014;66:169-72

12 Stachler RJ, Chandrasekhar SS, Archer SM, Rosenfeld RM, Schwartz SR, Barrs DM et al. Clinical practice guideline: sudden hearing loss. Otolaryngol Head Neck Surg 2012;146: $\mathrm{S} 1-35$

13 Weiss D, Böcker AJ, Koopmann M, Savvas E, Borowski M, Rudack C. Predictors of hearing recovery in patients with 
severe sudden sensorineural hearing loss. J Otolaryngol Head Neck Surg 2017; 46:27

14 Chau JK, Lin JR, Atashband S, Irvine RA, Westerberg BD. Systematic review of the evidence for the etiology of adult sudden sensorineural hearing loss. Laryngoscope 2010;120: $1011-21$

15 Ari-Even Roth D, Hildesheimer M, Roziner I, Henkin Y. Evidence for a right-ear advantage in newborn hearing screening results. Trends Hear 2016;20:1-8

16 Migirov L, Wolf M. In search of correlation between hand preference and laterality of hearing impairment in patients with otosclerosis. Eur Arch Otorhinolaryngol 2014;271: $2835-7$
Address for correspondence:

Dr Doron Sagiv,

Department of Otolaryngology - Head and Neck Surgery,

Sheba Medical Center,

Tel Hashomer 52621, Israel

Fax: +97235305387

E-mail: doron.sagiv@sheba.health.gov.il

Dr D Sagiv takes responsibility for the integrity of the content of the paper

Competing interests: None declared 